\title{
Ghaus M. Malik, MD
}

G haus M. Malik came to the United States in 1968 after graduating from King Edward Medical College in Lahore, Pakistan.

In. 1970 he began his general surgery residency at Henry Ford Hospital in Detroit, Michigan, followed by a neurosurgery residency from 1971 to 1975 . He then joined the Henry Ford Medical Group neurosurgery staff in 1975 and became board certified in neurosurgery in 1978.

Dr. Malik had a series of outstanding accomplishments at the Henry Ford Health System where he was appointed chief of the Division of Neurosurgery at Beaumont Hospital and maintained his position as vice chief of neurosurgery at Henry Ford Hospital. Dr. Malik has a strong interest and involvement in resident education at Henry Ford Hospital. Since 1975, he has been actively involved in the training of more than 50 residents graduating from the Henry Ford neurosurgery residency program.

In the field of neurosurgery, Dr. Malik specializes in cerebrovascular neurosurgery, especially arteriovenous malformations (AVMs) and aneurysms, as well as trigeminal neuralgia and complex brain and spinal cord tumors. His research interests include vasospasm, clinical outcomes of AVMs, and genetic mechanisms for familial AVMs.

Dr. Malik has published more than 80 articles and chapters in the neurosurgical literature. He has given numerous presentations at both national and international meetings and has been invited to lecture at many local and national institutions in countries including Argentina, India, Italy, Japan, Malaysia, Mexico, Pakistan, Russia, Singapore, Spain, South Korea, and Turkey.

Dr. Malik lives in Bloomfield Hills with his wife, Sahib Khatoon Malik, and their three children and six grandchildren.

Dr. Malik has had more than 25 years of involvement with the Islamic Association of Greater Detroit, having served as its president for 10 years and also as the chairman of its board of trustees. In addition, he has served as president of the Pakistan Association of
America, from which he has received the D i s t in gu is he d Community Service Award. Above all, his major interest has been the love and care of his patients and dedication to the Henry Ford Health System.

Dr. Malik has been a great supporter of IMANA and has enlightened its members with his extensive knowledge of neurosciences. He has

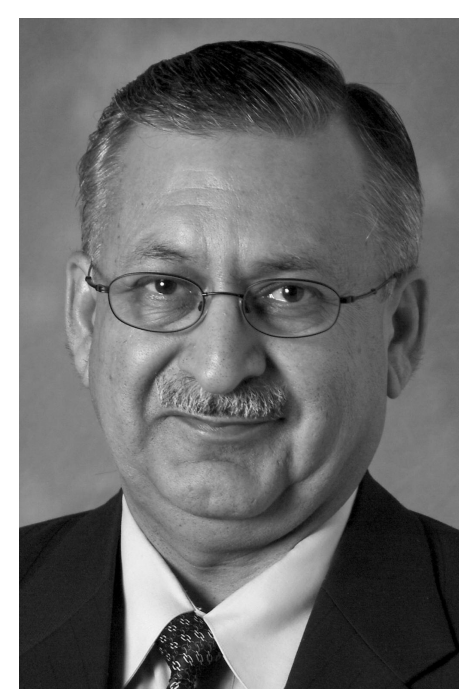

Ghaus M. Malik, MD delivered several memorial lectures at the annual IMANA conventions, most recently at the Beijing convention in 2006 and the Niagara Falls convention in 2007.

When asked what advice he has for his younger and upcoming colleagues, Dr. Malik outlined the following:

1. Pick a specialty for which you can develop a "passion" and you are going to feel proud of it in the long run.

2. Gain as much knowledge and training (such as fellowships) as possible to be accepted as an expert in some aspect of your specialty.

3. Get involved in research and contribute to the knowledge of medicine, both by teaching and publishing.

4. Start your patient database early (even as a resident) and collect information prospectively and diligently.

5. Periodically review the information, both for your own improvement and the education of others.

6. Periodically try to do critical assessment of your work and outcome of your patients. This is the only way to improve quality.

7. Adhere to the concept of compassionate care and 
get to know your patients.

8. Treat the patients, colleagues, and staff with respect and you will be equally respected. This is how a physician, especially a Muslim physician, should conduct himself or herself regardless.

9. Be involved in the running of the organization or institution where you are working and try to be the "voice of reason". If you prioritize the interests of patients and the institution, your personal interest will definitely be taken care of. It also helps develop organizational skills.

10. Devote a reasonable amount of time and resources to the betterment of your community and encourage your family also to be involved in community service.

11. Above all keep in mind that the knowledge and expertise you have are gifts from Allah dul and you will definitely be questioned as to how well you served humanity with that knowledge.
Personally, I am reminded of the advice given to me by Dr. Edward Meilman, who was the chairman of medicine at the hospital at which I did my residency. Dr. Meilman basically said the same thing as Dr Malik: "Develop a deep interest in any aspect of medicine and become the world's expert in it."

Personally that advice has served me very well, and I have tried to abide by that.

Profile submitted by

Faroque Ahmad Khan, MB, MACP

Member, Editorial Board, JIMA

Director Research and Publications

King Fahad Medical City

Riyadh, Saudi Arabia

Professor of Medicine

State University of New York

Stony Brook, New York 